\title{
Loss Analysis of Permanent Magnet Hybrid Brushless Machines With and Without HTS Field Windings
}

\author{
Chunhua Liu, Member, IEEE, K. T. Chau, Senior Member, IEEE, and Wenlong Li, Student Member, IEEE
}

\begin{abstract}
This paper presents and implements the power loss analysis of a new kind of permanent magnet hybrid brushless (PMHB) machines with and without using high-temperature superconductor (HTS) field windings. The circuit-field-torque time-stepping finite element method together with experiential equations is developed to perform power loss analysis of the PMHB machine. Experimentation is carried out to verify the proposed loss analysis.
\end{abstract}

Index Terms-Hybrid excitation, loss analysis, permanent magnet machine, superconducting machine.

\section{INTRODUCTION}

$\mathbf{P}$ ERMANENT magnet hybrid brushless (PMHB) machines are a new class of brushless machines, which can offer flexible flux control for various applications [1]-[3]. Due to the feature of tunable magnetic field, the power losses of these PMHB machines are very different from conventional brushless machines. However, over the years, their loss analyses are absent in literature. On the other hand, the advent of high-temperature superconductor (HTS) materials brings the conventional electric machines into a new era [4], [5].

The purpose of this paper is to propose and implement the loss analysis of the PMHB machine with and without using HTS field windings. Two different DC field windings, based on copper and the BSCCO-2223 HTS, will be adopted. The key of is to incorporate the circuit-field-torque time-stepping finite element method (CFT-TS-FEM) together with experiential equations to calculate various losses, including the conduction losses, iron losses, stray losses and mechanical losses. Both simulation and experimentation will be carried out to verify the proposed analysis.

\section{PMHB MAChINE TOPOLOGY}

Fig. 1 shows the structure of the proposed PMHB machine in which there are an outer rotor and two-layer inner stator [1]. The outer rotor comprises 24 salient poles without any windings or PMs, hence achieving high robustness. The outer-layer stator has 36 salient poles and accommodates the armature windings, whereas the inner-layer stator contains both of PMs and DC field windings. The distinct features of this PMHB machine can be summarized as follows:

Manuscript received October 18, 2009. First published April 08, 2010; current version published May 28, 2010. This work was supported and funded by a Grant (HKU 7105/07E) from the Research Grants Council, Hong Kong Special Administrator Region, China.

The authors are with the Department of Electrical and Electronics Engineering, The University of Hong Kong, China (e-mail: chualiu@eee.hku.hk).

Color versions of one or more of the figures in this paper are available online at http://ieeexplore.ieee.org.

Digital Object Identifier 10.1109/TASC.2010.2045116

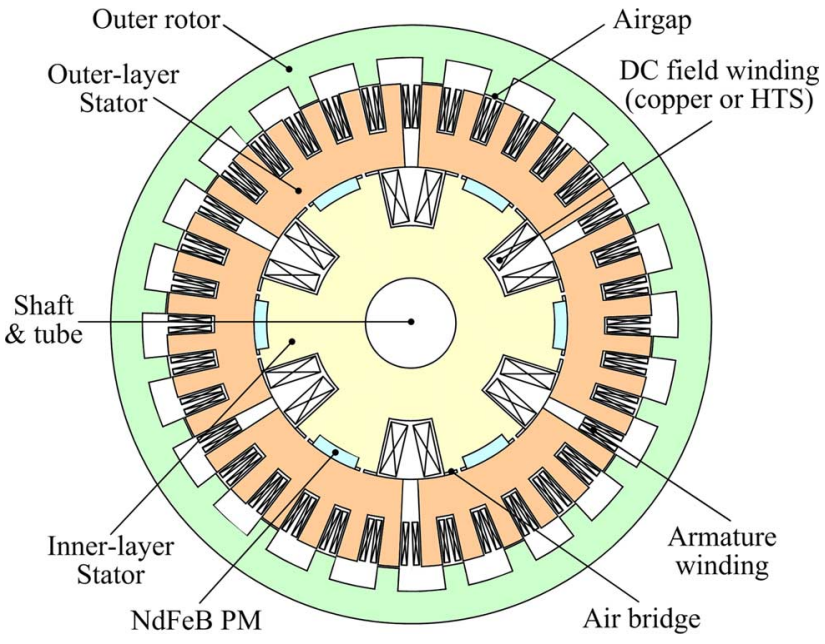

Fig. 1. Proposed PMHB machine topology.

- The proposed hierarchical structure, namely the outer rotor, outer-layer stator and inner-layer stator, can fully utilize the machine space.

- The outer-rotor topology can realize the concept of electromechanical isolation, namely the outside mechanical part and inside electrical part.

- By simply tuning the bidirectional DC field current, the machine can achieve a wide range of airgap flux regulation and hence a wide speed range.

- The machine can maintain reasonable operation when the PMs are accidentally demagnetized or the DC field windings are under open-circuit faults. So, it inherently possesses the capability of fault-tolerant operation.

- When adopting HTS field windings, the machine can offer high field current density and virtually zero field winding conduction loss, thus improving the power density and efficiency.

There are two major factors to justify the practicability of using HTS winding excitation, rather than copper field winding excitation, for the proposed PMHB machine. First, the original space for the copper field windings is large enough to accommodate the HTS field windings since the latter can offer much higher current density and hence require much smaller number of turns. Second, the effect of magnetic field excitation due to HTS field windings is the same as that due to copper field windings.

\section{LOSS ANALYSIS APPROACH}

Since the proposed PMHB machine adopts two field excitations to achieve the capability of online flux control, its power loss characteristics exhibit some special features. Firstly, the 
machine conduction loss and iron loss are both related with the magnetic field, and consequently with the DC field current. Secondly, for conventional copper field windings, although the field windings inevitably cause additional copper loss, they can regulate the magnetic field distribution to optimize the machine efficiency. Thirdly, for the BSCCO-2223 HTS field windings, the field winding loss is virtually zero, hence further improving the machine efficiency and power density.

In most literature, the loss analysis of electric machines has been focused on the iron loss analysis. In general, the iron loss analysis can adopt the direct calculation method or indirect experiential method [6], [7]. The direct calculation method usually employs the FEM combined with complex eddy-current and hysteresis models to calculate the eddy-current loss and hysteresis loss. In contrast, the experiential method usually adopts experiential equations to calculate the eddy-current loss and hysteresis loss. For the proposed PMHB machine, the direct calculation method is ill-suited since it makes the whole CFT-TS-FEM model too complicated and time-consuming for analysis under online flux control. Thus, after the CFT-TS-FEM is employed to calculate the magnetic field, experiential equations are adopted to determine the associated eddy-current loss and hysteresis loss.

The electromagnetic field equation of the proposed machine is governed by:

$\Omega: \frac{\partial}{\partial x}\left(v \frac{\partial A}{\partial x}\right)+\frac{\partial}{\partial y}\left(v \frac{\partial A}{\partial y}\right)=-J-v\left(\frac{\partial B_{r y}}{\partial x}-\frac{\partial B_{r x}}{\partial y}\right)+\sigma \frac{\partial A}{\partial t}$

where $\Omega$ is the field solution region, $A$ the magnetic vector potential, $J$ the current density, $\nu$ is the reluctivity, $\sigma$ the electrical conductivity, and $B_{r x}, B_{r y}$ the remnant flux density components of PMs along the $x$-axis and $y$-axis, respectively.

In the regions of the airgap, air bridges, stator iron core and rotor iron core, there is no current density involved when the eddy current is neglected. It should be noted that this neglect is to ease the calculation of the magnetic field distribution. Afterwards, the eddy-current loss of the stator core and rotor core is calculated by using the experiential method. Thus, the field equation in these regions can be expressed as:

$$
\frac{\partial}{\partial x}\left(v \frac{\partial A}{\partial x}\right)+\frac{\partial}{\partial y}\left(v \frac{\partial A}{\partial y}\right)=0
$$

In the region of PMs, the field equation can be written as:

$\frac{\partial}{\partial x}\left(v \frac{\partial A}{\partial x}\right)+\frac{\partial}{\partial y}\left(v \frac{\partial A}{\partial y}\right)=-v\left(\frac{\partial B_{r y}}{\partial x}-\frac{\partial B_{r x}}{\partial y}\right)+\sigma_{P M} \frac{\partial A}{\partial t}$

where $\sigma_{P M}$ is the electrical conductivity of PMs. Since the PMs are buried in the inner-layer stator, the eddy current is negligible, namely $\sigma_{P M}=0$. Again, this neglect is to ease the calculation of the magnetic field distribution. The corresponding eddy-current loss is calculated afterwards.

In the region of armature windings in the outer-layer stator, the field equation is given by:

$$
\frac{\partial}{\partial x}\left(v \frac{\partial A}{\partial x}\right)+\frac{\partial}{\partial y}\left(v \frac{\partial A}{\partial y}\right)=-J=-\frac{i}{S}
$$

where $i$ is the phase current, and $S$ the conductor area of each turn of phase winding.

In the region of copper field windings in the inner-layer stator, the field equation can be written as:

$$
\frac{\partial}{\partial x}\left(v \frac{\partial A}{\partial x}\right)+\frac{\partial}{\partial y}\left(v \frac{\partial A}{\partial y}\right)=-J=-\frac{i_{f}}{S_{f}}
$$

where $i_{f}$ is the DC field current, and $S_{f}$ the conductor area of each turn of DC field winding. For the case of HTS field windings, according to the Meissner effect, the magnetic field in the region is virtually zero.

The circuit equations of the machine are governed by:

$$
\begin{aligned}
u & =R i+L_{e} \frac{d i}{d t}+e \\
e & =\frac{l}{S} \iint_{\Omega_{e}} \frac{\partial A}{\partial t} d \Omega \\
i^{\prime} & =N^{\prime} i \\
i^{\prime} & =-\frac{\sigma}{N l}\left(S\left(N^{\prime} u+R_{e} i^{\prime}+L_{e} \frac{d i^{\prime}}{d t}\right)+N l e\right)
\end{aligned}
$$

where $u$ is the applied voltage per phase, $R$ the resistance per phase, $R_{e}$ and $L_{e}$ the resistance and inductance of the end winding per phase, $e$ the induced EMF per phase, $i^{\prime}$ the total current per phase in the solution area, $l$ the axial length of the iron core, $\Omega_{e}$ the total cross-sectional area of conductors per phase, $N$ the number of conductors per phase, and $N^{\prime}$ the number of conductors per phase in the solution area.

The motion equation of the machine is given by:

$$
J_{m} \frac{d \omega}{d t}=T_{e}-T_{L}-\lambda \omega
$$

where $J_{m}$ is the moment of inertia, $\omega$ the rotor speed, $T_{e}$ the electromagnetic torque, $T_{L}$ the load torque, and $\lambda$ the damping coefficient. By using the Maxwell stress tensor method, $T_{e}$ can be easily calculated by:

$$
T_{e}=\frac{l}{\mu_{0}} \oint r^{2} B_{r} B_{\theta} d \theta
$$

where $\mu_{0}$ is the permeability of free space, $r$ the average of the inner and outer radius of the airgap, $B_{r}$ and $B_{\theta}$ the normal and tangential components of the airgap flux density.

Consequently, after discretizing (2)-(11), the whole CFT-TS-FEM model can be deduced. Hence, the magnetic field distribution and various electromagnetic performances of the machine can be obtained.

The power losses of the proposed PMHB machine include the conduction losses, iron losses, stray losses, and mechanical losses. The iron losses are composed of the eddy-current loss and the hysteresis loss.

For the case with copper field windings, the conduction losses are the copper losses due to the stator windings and DC field windings, which can be represented by the experiential equation as:

$$
P_{C u}=m R i^{2}+R_{f} i_{f}^{2}
$$

where $m$ is the number of phases, and $R_{f}$ the resistance of the DC field winding. So, these copper losses can be easily calculated by using the CFT-TS-FEM.

For the case with HTS field windings, the conduction losses are mainly due to the copper loss of stator windings, whereas the conduction loss of HTS field windings is negligible. The reason 
is actually due to the benefit of HTS material. Nevertheless, the HTS field windings inevitably contribute to iron losses.

The eddy-current loss of the iron core can be described by the experiential equation as:

$$
P_{E d}=\frac{\pi^{2} b^{2}}{6 \rho_{1} \rho_{2}} G_{F e} f^{2} B_{\sigma}^{2}
$$

where $b$ is the thickness of the iron, $\rho_{1}$ the resistivity of the iron, $\rho_{2}$ the density of the iron, $G_{F e}$ the weight of the iron, $f$ the supply frequency, and $B_{\sigma}$ the flux density of the iron. Thus, under a given speed, the eddy-current loss depends on $B_{\sigma}$ which can be readily deduced from the CFT-TS-FEM results.

The hysteresis loss is caused by varying magnetization of ferromagnetic material, which can be described by the experiential equation as:

$$
P_{H y}=k_{1} G_{F m} f B_{\sigma}+k_{2} G_{F m} f B_{\sigma}^{2}
$$

where $k_{1}$ and $k_{2}$ are the coefficients of the material, and $G_{F m}$ the weight of the material. Hence, under a given speed, the hysteresis loss varies with $B_{\sigma}$, which can also be easily deduced from the CFT-TS-FEM results.

The stray losses are additional losses caused by the load current due to changes in metallic materials. Such losses are usually quite small and can be represented by the experiential equation as:

$$
P_{S t}=k_{3} f^{2} i^{2}
$$

where $k_{3}$ is the coefficient of stray losses. So, it can be easily calculated by using the CFT-TS-FEM.

The mechanical losses are due to friction and windage, which are independent of those electrical variables. In general, according to the experiential equation, it can be expressed as:

$$
P_{M e}=k_{4}\left(\frac{60 \omega}{2 \pi}\right)^{2}
$$

where $k_{4}$ is the coefficient of mechanical losses. It can be easily calculated by using the CFT-TS-FEM.

Therefore, according to the experiential equations given by (12)-(16), the power losses of the proposed PMHB machine can be readily calculated.

\section{VERIFICATION RESULTS}

To verify the proposed loss analysis, both simulation and experimentation are carried out. For simulation, the characteristics and power losses of the PMHB machine with and without using HTS field windings are analysed by using the CFT-TS-FEM together with experiential equations.

For experimentation, the PMHB machine using copper field windings is prototyped as shown in Fig. 2 for direct measurement. Then, by ignoring the copper loss due to copper field windings, the prototype can emulate the performance of the machine using HTS field windings since their magnetic field excitations are the same.

The machine prototype is mechanically coupled with a DC dynamometer which can real-time provide four-quadrant mechanical load for experimentation. So, for a given setting of load torque and speed, the output power of the machine can readily

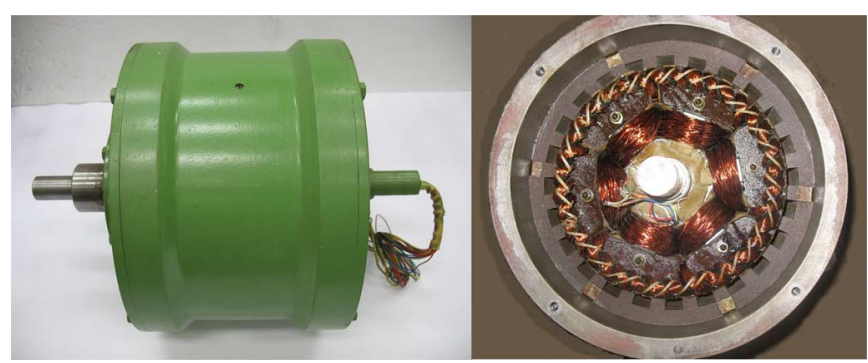

Fig. 2. PMHB machine prototype.
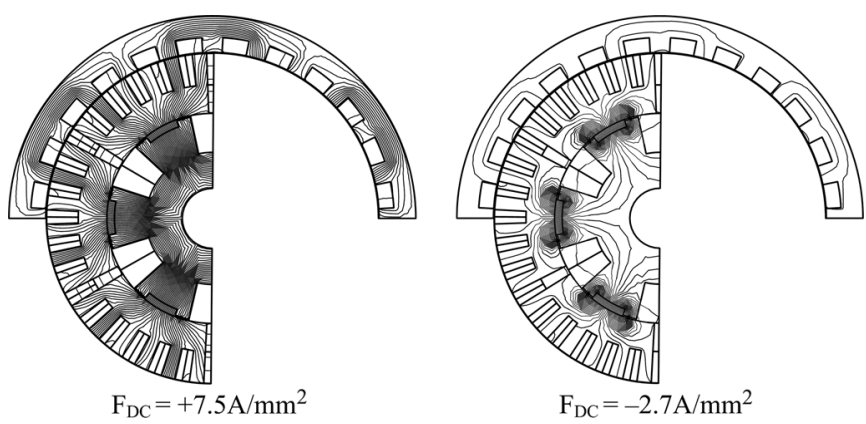

Fig. 3. Magnetic field distributions using different DC field currents.

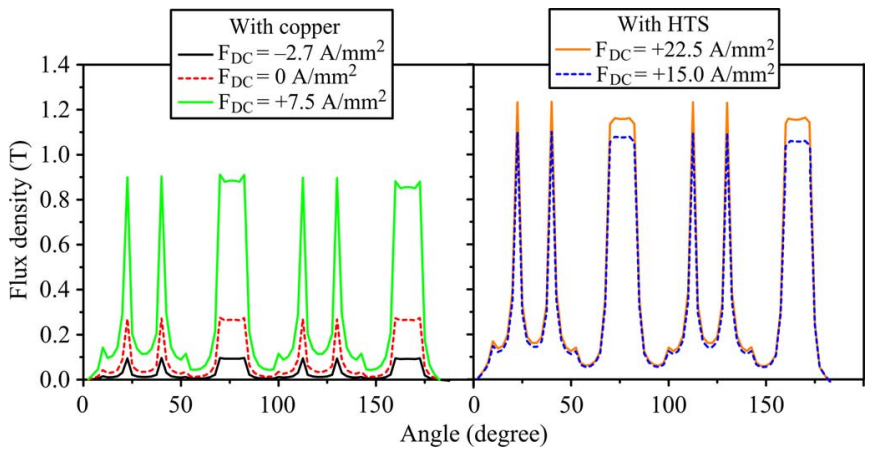

Fig. 4. Airgap flux density distributions with and without HTS.

be determined, while the input power of the machine can be directly measured by using a power analyzer. Hence, the power loss and efficiency of the PMHB motor can be deduced.

Firstly, the magnetic field distributions of the proposed PMHB machine with different DC field currents are shown in Fig. 3. It can be observed that the magnetic field can be effectively controlled. Fig. 4 shows the corresponding airgap flux density waveforms, which confirms that a wide range of airgap flux regulation can be obtained. Also, with the use of HTS field windings, the airgap flux density can be further increased up to the saturation level of the iron core.

Secondly, the simulated no-load EMF waveforms during generating are shown in Fig. 5. It can be found that the PMHB machine can maintain the constant voltage output over a wide speed range because of its flux control capability. Also, with the use of HTS field windings, the EMF can be significantly increased. Nevertheless, when magnetic saturation of iron core occurs, the EMF cannot be further increased by using higher field current density.

Thirdly, the power characteristics, namely the input power and power loss, of the machine during motoring when using the 


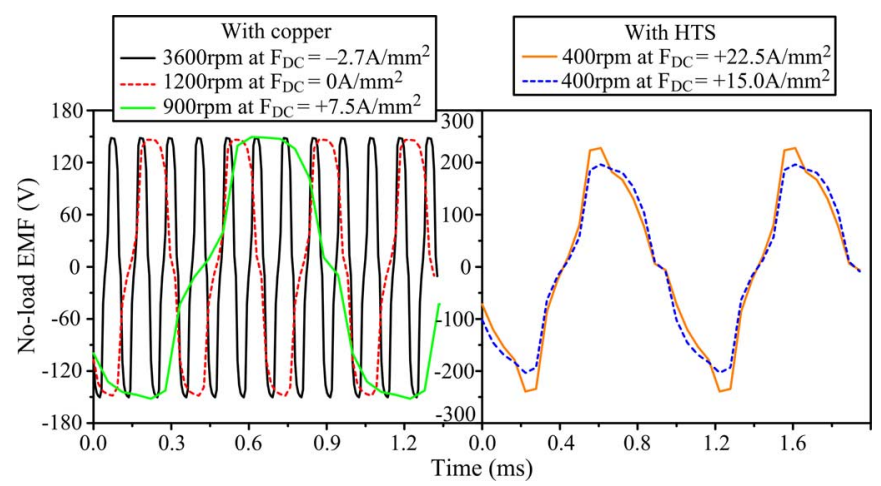

Fig. 5. No-load EMF waveforms with and without HTS.

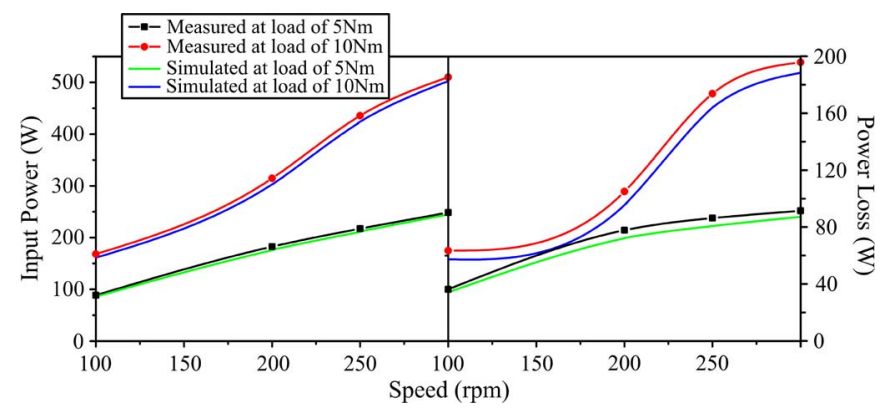

Fig. 6. Power characteristics using copper field windings.

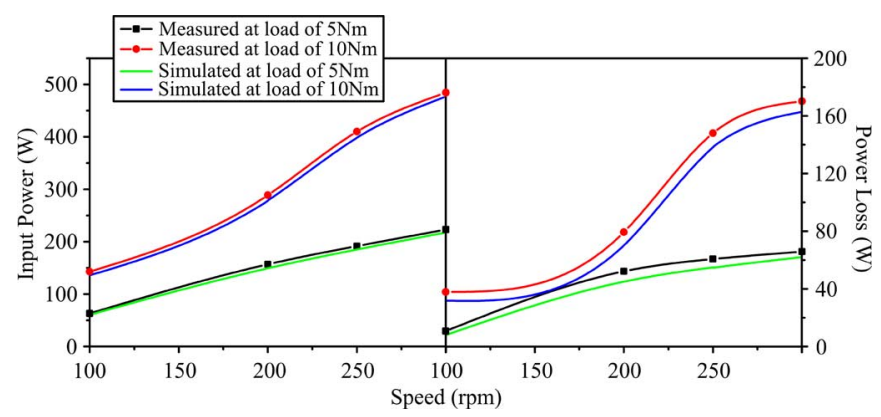

Fig. 7. Power characteristics using HTS field windings.

copper and HTS field windings with the same current density of $2.3 \mathrm{~A} / \mathrm{mm}^{2}$ are shown in Figs. 6 and 7, respectively. It can be seen that the simulated results well agree with the measured ones, hence verifying the accuracy of the proposed loss analysis. Also, it can be observed that the use of HTS field windings to supersede copper field windings can reduce the input power from $85.9-510.0 \mathrm{~W}$ to $60.3-484.4 \mathrm{~W}$, and also reduce the power loss from 33.5-195.8 W to 7.9-170.2 W. Moreover, as shown in Fig. 8, the corresponding efficiency is improved from $57-70 \%$ to $63-87 \%$.

It should be noted that the measured power loss and efficiency of the PMHB machine using HTS field windings as shown in

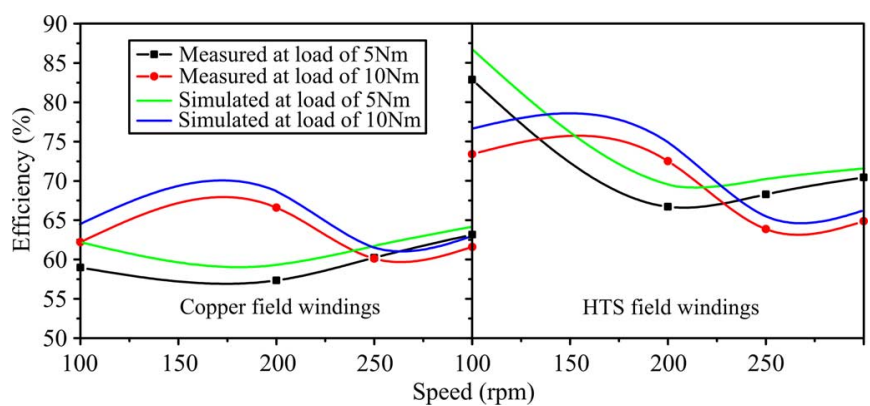

Fig. 8. Efficiency characteristics using copper and HTS field windings.

Figs. 7 and 8 are emulated by ignoring the copper loss due to the copper field windings of the prototype. This emulation can avoid the hardware construction of HTS field windings while enable the comparison of their power losses. It is acceptable since the HTS field windings involve insignificant conduction loss.

\section{CONCLUSION}

In this paper, the loss analysis has been proposed and implemented for PMHB machines with and without using HTS field windings. The key is to employ the CFT-TS-FEM together with the experiential equations. Without taking into account the required power to cool the HTS field windings, it can be observed that the use of HTS field windings can significantly reduce the power loss and improve the efficiency of the PMHB machine. If taking into account the cooling power, the improvement will be reduced accordingly.

\section{REFERENCES}

[1] C. Liu, K. T. Chau, J. Z. Jiang, and L. Jian, "Design of a new outer-rotor permanent magnet hybrid machine for wind power application," IEEE Trans. Magn., vol. 44, no. 6, pp. 1494-1497, Jun. 2008.

[2] K. T. Chau, Y. B. Li, J. Z. Jiang, and S. Niu, "Design and control of a PM brushless hybrid generator for wind power application," IEEE Trans. Magn., vol. 42, no. 10, pp. 3497-3499, Oct. 2006.

[3] K. T. Chau, Y. B. Li, J. Z. Jiang, and C. Liu, "Design and analysis of a stator-doubly-fed doubly-salient permanent-magnet machine for automotive engines," IEEE Trans. Magn., vol. 42, no. 10, pp. 3470-3472, Oct. 2006.

[4] T. Nakamura, H. Miyake, Y. Ogama, G. Morita, I. Muta, and T. Hoshino, "Fabrication and characteristics of HTS induction motor by the use of $\mathrm{Bi}-2223 / \mathrm{Ag}$ squirrel-cage rotor," IEEE Trans. Appl. Supercond., vol. 16, no. 2, pp. 1469-1472, Jun. 2006.

[5] A. B. Abrahamsen, N. Mijatovic, E. Seiler, M. P. Sorensen, M. Koch, P. B. Norgard, N. F. Pedersen, C. Traeholt, N. H. Andersen, and J. Ostergard, "Design study of $10 \mathrm{~kW}$ superconducting generator for wind turbine applications," IEEE Trans. Appl. Supercond., vol. 19, no. 3, pp. 1678-1682, Jun. 2009.

[6] S. Niu, K. T. Chau, and J. Z. Jiang, "Analysis of eddy-current loss in a double-stator cup-rotor PM machine," IEEE Trans. Magn., vol. 44, no. 11, pp. 4401-4404, Nov. 2008.

[7] D. M. Ionel, M. Popescu, S. J. Dellinger, T. J. E. Miller, R. J. Heideman, and M. I. McGilp, "On the variation with flux and frequency of the core loss coefficients in electrical machines," IEEE Trans. Ind. Appl., vol. 42, no. 3, pp. 658-667, May/Jun. 2006. 